Seneca's Oedipus and the

dissolution of the points of reference

\title{
El Edipo de Séneca y la disolución de los referentes
}

\author{
Ignacio Pajón Leyra
}

Universidad Complutense de Madrid ipajon@filos.ucm.es

DOI: http://doi.org/10.15366/bp2019.22.020

Bajo Palabra. II Época. № 22. Pgs: 375-390

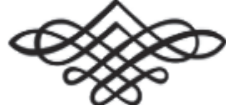


Recibido: 28/10/2017

Aprobado: 02/10/2019

\section{Resumen}

El estudio de las obras dramáticas de Séneca exige su valoración no sólo desde el punto de vista de su cualidad estética teatral sino, ante todo, desde la perspectiva de su profundo pensamiento filosófico. El presente artículo analiza el marco original que Séneca presenta de la noción de lógos como fuerza arbitraria, inexorable e irracional en su tragedia Edipo. Esta obra, articulada en torno a la reflexión sobre la ignorancia y sus consecuencias éticas y vitales, muestra de forma provocativa una disolución de los referentes antiguos mediante una elaborada técnica de inmersión conceptual del espectador en la trama narrativa y filosófica del mito clásico.

Palabras clave: Séneca; estoicismo; Edipo; lógos; tragedia romana.

\section{Abstract}

The study of the Seneca's plays requires it valuation not only from the point of view of his theatrical aesthetic quality but, above all, from the perspective of his deep philosophical thought. This article analyzes the original frame that Seneca shows of the concept of lógos as an arbitrary, inexorable and irrational force in his tragedy Oedipus. This work, structured around a reflexion on the ignorance and its ethical and vital consequences, shows in a provocatively way a disolution of the ancient reference points through the elaborated technique of the conceptual immersion of the viewer in the narrative and philosophical frame of this classical myth.

Keywords: Seneca; stoicism; Oedipus; lógos; roman tragedy. 
$\mathrm{E}$ s incuestionable que toda la obra dramática de Lucio Anneo Séneca debe ser concebida y analizada dentro de sus presupuestos filosóficos. Su trabajo literario nace vinculado a un sistema de pensamiento, el estoico, que lo vertebra y le da sentido, ${ }^{1}$ de tal modo que el Séneca trágico no puede comprenderse adecuadamente sin atender al Séneca filósofo. Es cierto que, en su escritura teatral, sus tragedias se muestran como profundas deudoras de la tradición dramática griega. Pero al tiempo resulta igual de evidente que fueron compuestas en gran medida como medio de expresión de una visión del mundo y del hombre, y que esa visión es congruente con la que expone en sus tratados, y nada difícil de identificar como estoicismo.

El estoicismo de Séneca, con todo, guarda importantes diferencias con la original formulación planteada inicialmente en Atenas por autores como Zenón de Citio, Cleantes de Asos o Crisipo de Solos durante el siglo III a. C. ${ }^{2}$ Con la matización y permeabilización producida en la escuela a lo largo de los ańos se introdujeron en ella elementos procedentes de otras corrientes, y la propia formación intelectual de Séneca ańadió nuevas influencias y aportes que convirtieron el conjunto de su pensamiento en algo original y diferenciado. ${ }^{3}$ Pero aún en su peculiaridad, el estoicismo de Séneca juega para su literatura dramática un papel de marco de interpretación que no puede ser dejado de lado.

En el caso de su Edipo, en concreto, este papel resulta indispensable como elemento a tener en cuenta para comprender la intencionalidad misma de la obra. Como es sabido, el texto del Edipo senequiano supone una reinterpretación del mito griego de Edipo muy alejada del mayor referente trágico hoy conservado sobre este material mitológico: el Edipo Rey de Sófocles.

En efecto, el Edipo de Séneca es un personaje más atormentado, torturado por la culpa y la sospecha y sumergido en un ambiente más oscuro, inquietante y en ocasiones aterrador. El tono expresivo de la obra es más violento y explícito que el de Sófocles, llegando en ocasiones a poder ser calificado de sangriento. Y a diferencia

\footnotetext{
${ }^{1}$ Egermann, F. "Seneca als Dichterphilosoph". Neue Jahrb., 3 (1940), 18-36.

2 Arnim, H. von. Stoicorum veterum fragmenta. 4 vols. Teubner, Stuttgart, 1923. Cappelletti, A. J. Los estoicos antiguos, Madrid, Gredos, 1996. Véase también Sellars, J. Stoicism, Berkeley/Los Angeles, University of California Press, 2006.

${ }^{3}$ Cfr. Veyne, P. Séneca y el estoicismo, México, Fondo de Cultura Económica, 1995, 47 y ss.; Griffin, M. T. Séneca, a Philosopher in Politics, Oxford, Claredon, 1976.
} 
del trágico griego, Séneca juega con la angustia del lector ${ }^{4}$ sometiendo a los personajes a un proceso de pesquisa de la causa de la peste que asola Tebas en el que la incertidumbre e ignorancia de los intervinientes en la obra no hace sino aumentar la ansiedad con la que el proceso es contemplado "desde fuera".

Los postulados sobre los que se asienta esta forma de contemplar la tragedia, más desgarrada y opresiva que la tradicional expresión trágica de Grecia, proceden en su mayoría del estoicismo, pero al tiempo se distancian en parte de la versión estoica más ortodoxa. Así, las ideas filosóficas de Séneca sobre el cosmos, el orden, el tiempo, el ser humano, la virtud, la vida y la muerte se convierten en puntos de articulación cruciales para su obra trágica. ${ }^{5} \mathrm{Y}$ entre esas ideas no es de importancia menor un modo específico de comprender un concepto tan nuclear para los estoicos como es el lógos.

El lógos estoico, a un tiempo razón, proporción, divinidad y destino, rige un mundo cambiante muy próximo al heraclitiano. Porque hay un lógos, el devenir no puede ser considerado caótico, azaroso ni irracional. Pero ese lógos que todo lo gobierna ${ }^{6}$ es, todo él, razón y virtud, y se opone diametralmente a la maldad y la irreflexión. El mal, por tanto, procede solo del hombre que actúa de un modo no conforme con ese lógos universal; y de este modo, como para Sócrates, ${ }^{7}$ para el estoico antiguo el malvado es solo el ignorante, o con mayor precisión el que no conoce ni comprende la razón cósmica que se manifiesta tras el devenir de la naturaleza.

Sin embargo, la visión que ofrece Séneca del lógos en esta tragedia parece, en un primer momento, separarse de esa pura racionalidad benévola para convertirse en una fuerza arrebatadora, arbitraria y que no se manifiesta ni como benigna ni como racional. Y el motivo de que esto ocurra no aparenta ser solo la mera congruencia con el destino trágico griego entendido como fuerza ciega irrefrenable. Se trata, a nuestro entender, de un auténtico "efecto de inmersión" equivalente a los que tan profundamente han marcado el teatro actual a raíz de la obra dramática de Antonio Buero Vallejo. ${ }^{8}$

\footnotetext{
${ }^{4}$ Se trata, aquí, de un lector y no de un espectador, dado que la obra de Séneca fue concebida más para la lectura pública en las reuniones sociales de la intelectualidad romana que para su completa puesta en escena teatral.

5 Marti, B. M. "The prototypes of Seneca's tragedies". Classical Philology 42 (1947), 1-16.

${ }^{6}$ Sobre esto, véase el Himno a Zeus de Cleantes, conservado por Estobeo (Églogas, I 1, 12). Vid. Arnim, H. v. Stoicorum veterum fragmenta, Stuttgart, Teubner, 1923, Vol. I, 537; Cappelletti, A. J. Los estoicos antiguos, Madrid, Gredos, 1996. pp. 288-292.

7 "El origen concreto del estoicismo está en Sócrates (...); es claro que sin la actitud socrática no hubiera sido posible el hombre de la Stoa." Marías, J. "Introducción a la filosofía estoica”, en Séneca, Sobre la felicidad, Madrid, Alianza, 1984. p. 25.

${ }^{8}$ Los efectos de inmersión son un recurso dramático que permite a Buero Vallejo conseguir que el público se identifique desde un nivel básico con un personaje superando la objetividad en el punto de vista dramatúrgico-narrativo, de modo que el espectador participa incluso sin saberlo de la problemática a la que atańe la obra. Véase Doménech, R. El teatro de Buero Vallejo: una meditación española, Madrid, Gredos, 1979; Dixon, V. "Los
} 
En Buero, el efecto de inmersión al que se somete al espectador es, en la mayoría de los casos, sensorial. Así ocurre con la ceguera que el público comparte con los protagonistas en las escenas culminantes de En la ardiente oscuridad o El concierto de San Ovidio, o con la sordera del personaje de Goya que se extiende a los espectadores cuando él está en escena en El sueño de la razón. Pero en ocasiones se convierte también en un efecto de inmersión "mental", como el delirio del propio Goya en la misma obra o las alucinaciones que trastocan la visión del mundo de Tomás, protagonista de La fundación.

En una línea similar a estas últimas, quizá podamos interpretar algunos rasgos de la tragedia de Séneca en general, y del Edipo en particular, como una suerte de "efecto de inmersión conceptual". Y la clave interpretativa para valorar esta cuestión en su justa medida reside en hacernos conscientes de que, como diálogo teatral para ser pronunciado en alto, el elemento estructurador de esta tragedia es la voz; y en especial la voz que expresa el punto de vista de quien transgrede el dictado del lógos.

El mito de Edipo, de este modo, está aquí expuesto desde el punto de vista del propio protagonista, y subsidiariamente desde la óptica de la sociedad que lo acoge y a la cual su falta se ha transmitido en la forma de un "miasma" o contaminación que provoca la peste y que requiere purificación. Es decir, la visión que del destino se transmite en esta tragedia es la que tienen de él los "malvados" de los que habla Cleantes, los que actúan contra la divinidad porque no comprenden que la virtud es necesaria, que la razón se identifica con el bien, y que esta razón que todo lo gobierna es la divinidad misma.

Por ello, al igual que aquellos que transgreden el dictado del lógos (que son aquellos a los que la tragedia presta su voz antes de mostrar su fatal yerro), al igual que los que ignoran la pauta del universo consideran que la divinidad es diferente del destino, y que este último es arbitrario, funesto e irracional, nosotros como lectores corremos el riesgo de no ver más allá, inmersos en su limitada óptica.

No puede un dios cambiar el curso de unas cosas que van encadenadas a sus causas.

Hay para cada cosa un orden fijo que no puede cambiar plegaria alguna. ${ }^{9}$

Así se expresa el coro hacia el final de la tragedia, transmitiendo un punto de vista social y colectivo. En este pasaje se encuentran algunas de las aducidas dife-

efectos de inmersión en el teatro de Antonio Buero Vallejo: una puesta al día”, Anthropos: Boletín de información y documentación, 79 (1987), 31-36.

9 Séneca, Edipo, 989-992. (Para las traducciones de obras de Séneca en este artículo seguiremos la edición de Séneca, Tragedias. 2 vols. Traducción de Jesús Luque Moreno, Madrid, Gredos, 1979-1980.) 
rencias con el estoicismo más ortodoxo: una diferencia esencial entre la divinidad y el curso de los acontecimientos; una absoluta impotencia de esta divinidad; una interpretación de la causalidad como concatenación férrea de acontecimientos en la que no se percibe racionalidad; y finalmente una inutilidad completa de la piedad religiosa, derivada de todo lo anterior.

Para causar el efecto dramático buscado todas estas características de la divinidad y del destino son, sin duda, imprescindibles. Pero no es tanta la necesidad de defender que estas características de hecho se dan como la de mostrarlas al público y sumergirlo en el ambiente desesperanzado que ellas generan. Si Séneca defiende o no de hecho de manera efectiva dichas características es algo ya discutido por Sklenár. ${ }^{10}$ Aunque en lo básico su interpretación de un Séneca distópico nos parece correcta, no así su hipótesis de una naturaleza anti-estoica del mundo en el que la tragedia se desarrolla. ${ }^{11}$ La obra de Séneca muestra, en efecto, un mundo diferente del estoico: el equivocado mundo en el que cree vivir el ignorante y malvado. Es decir, el hecho de que Séneca muestre esa visión del mundo en su obra literaria no implica, en nuestra opinión, que comparta esa visión del mundo desde un punto de vista doctrinal. Y si la muestra en su obra dramática puede que se deba a su intención de hacer patente cómo es una visión equivocada de la naturaleza y del destino. La causa de dicha intención por parte del filósofo no es fácil de entender sin tener en cuenta el contexto dramático de dichos pasajes y la tarea ejemplificadora que los envuelve. En efecto, el motivo de su escritura es, antes que nada, el de conducir al lector del texto a contemplar la angustia de quien da la espalda a la razón que rige la naturaleza. ${ }^{12} \mathrm{Y}$ por ello el lector debe ser sumergido en una visión del mundo que no por contrafáctica es menos frecuente.

Edipo, en efecto, es el más claro ejemplo cultural de transgresor del dictado del lógos. Su acto violento e irreflexivo de matar a Layo, su padre, es una violación a un tiempo de las normas de los hombres y de las leyes de la naturaleza de las que aquellas, en general, se muestran como simples corolarios. No hay aquí, como en Antígona, conflicto entre las leyes de los hombres y las de los dioses. Desde cualquier punto de vista, el acto de Edipo es una transgresión del lógos-nómos contraria a toda sabiduría. El hecho de que la lleve a cabo ignorando que Layo es en realidad

${ }^{10}$ Véase Sklenár, R. J. “Seneca, Oedipus 980-993: How Stoic a Chorus?”, Classical Journal, vol. 103, no 2 (20078), 183-194.

11 Idem, 193.

${ }^{12}$ De otro modo, si concordásemos con Sklenár en que la tragedia es por completo una pieza escrita en una suerte de fantasía anti-estoica, resultaría difícil concebir por qué podría Séneca haberla escrito. Esto no obsta, sin embargo, para que sí concordemos con un él en la diferencia que resalta en su artículo entre la visión del cosmos del coro y la del propio Séneca (Idem, 194), aunque quizá con una ligera diferencia de matiz en los motivos subyacentes. 
su padre no solo no la mitiga, sino que contribuye a ejemplificar esa tesis socrático-estoica de que quien obra mal es por ignorancia. Y lo mismo puede decirse del incesto que, como consecuencia, Edipo termina cometiendo con su madre y ahora esposa, Yocasta.

El atentado que ambas transgresiones implican no es contra la mera legalidad humana, sino que, en su sentido más profundo, debe considerarse como un atentado contra el orden mismo del universo. Por ello, la obra entera está plagada de expresiones que denotan desconcierto, confusión, desorientación o pérdida de referencias.

Entre ellas, destaca con fuerza el extenso pasaje en el que Manto describe al ciego Tiresias las señales que proporcionan las vísceras del sacrificio. Se trata de una descripción cruda, plena de detalles, en la que al tiempo se hace presente el funesto destino que aguarda a los labdácidas y se evidencia, por la perturbación del orden natural de las cosas, el alcance cósmico y físico del crimen de Edipo.

Manto.- Padre, ¿qué es esto? Las entrañas no tiemblan como siempre, agitadas por un ligero movimiento, sino que sacuden las manos por completo y la sangre vuelve a saltar de nuevo de las venas. (...) Está cambiado el orden natural, nada queda en su sitio; al contrario, todo está al revés: sin nada de aire yace el pulmón ensangrentado en la parte derecha, no ocupa el corazón la región izquierda, el redaño no cubre con blanda envoltura los grasos repliegues de las vísceras, los órganos sexuales están trastocados y el útero sin ley alguna. ${ }^{13}$

En el breve extracto del pasaje que hemos citado se aprecia suficientemente que el signo principal del mal augurio es, según se nos expone, el desorden. Nada está donde debería ni hace lo que le es propio; nada ocupa su lugar ni desempeña su papel natural. Como si la phýsis misma de la víctima sacrificial hubiese perdido su coherencia, todo es extraño, siniestro y monstruoso.

El sacrificio, que el propio Edipo llama "terrorífico" ${ }^{14}$, no sirve, de este modo, para calmar el ánimo del rey de Tebas, sino que por el contrario multiplica la inquietud. Por ello, se produce el recurso a un rito necromántico, con todo lo que de tabú implica el evocar a los muertos y a los dioses infernales.

"Hay que intentar otro camino: a él en persona hay que evocarlo desde las regiones de la noche eterna y hacerlo salir del Erebo para que nos señale al autor del asesinato.

Tiene que abrirse la tierra, hay que suplicar a la divinidad implacable de Plutón, hay que arrastrar hasta aquí fuera al pueblo de la infernal Éstige." ${ }^{15}$

13 Edipo, 354-373.

${ }^{14}$ Edipo, 385.

15 Edipo, 392-397. 
En sí mismo, el ritual de invocación que aquí se representa supone ya una nueva forma de confusión cósmica: borra los límites entre el mundo de los vivos y el de los muertos; establece una conexión entre lo por completo heterogéneo; permite la comunicación entre dos espacios, el pre y el post-mortem, el de lo que aún es natural y el de lo que ya ha dejado de serlo, espacios que de por sí no deberían poder comunicarse. Se difuminan, de este modo, las fronteras estructurales que vertebran el cosmos, ejemplificando la vulneración del orden natural del lógos.

La superficie terrestre, ámbito propio de lo vivo y lo humano, tendría que mantenerse de por sí deslindada de lo subterráneo-inframundano, ámbito de lo muerto y lo monstruoso. Por ese motivo las divinidades infernales carecen de culto, por lo general, en la religión grecorromana, pues evocarlas es hacer presente lo infausto que debe permanecer ausente. $\mathrm{Y}$ a quien gobierna esas regiones, el dios Hades, ni siquiera se le suele nombrar. El apelativo "Plutón" por el que aparece nombrado en esta tragedia, más que el nombre romano de dicho dios es en realidad una suerte de eufemismo, un no-nombre griego por el que referirse a él sin mencionarlo para evitar su evocación: "el rico". ${ }^{16}$ Apelativo equivalente a los de Clímeno ("el célebre"), Polídegmon ("el que recibe a muchos"), o Eubouleo ("el buen consejero") por los que también era denominado.

Esta divinidad, rey del inframundo, no personifica la mera muerte (algo que ya está personificado en la figura de Thánatos), sino más bien el gobierno de todo lo vinculado con lo subterráneo, lo profundo y, por lo tanto, lo secreto.

No hubo en Grecia ni en Roma templos ni altares dedicados al culto de Hades-Plutón. Su mera presencia ya es funesta, por lo que al tiempo se evita ofenderle y se evita rendirle culto. Su representación iconográfica es infrecuente hasta lo excepcional. ${ }^{17}$ Por lo que la alusión a un rito necromántico dedicado a su figura en una obra como la de Séneca no puede dejar de causar un especial efecto de temor, sobrecogimiento y sensación de transgresión en el ciudadano romano que la contempla. Pero no es solo para causar ese efecto para lo que está presente este rito en el texto. Además, debe tenerse presente que Hades es el dios de lo invisible, de lo que está oculto. El mundo infernal es también aquella profundidad inabarcable cuyo conocimiento nos está vedado. Se manifiesta, así, a través de esta divinidad, lo "profundo" como invisible, incognoscible, oscuro, oculto, insuperable y laberíntico. Tal y como Heráclito expresa en una de sus más famosas sentencias, "la auténtica na-

\footnotetext{
${ }_{16}$ Este apelativo hace referencia al hecho de que todo lo más valioso parece proceder del espacio de lo subterráneo, y por lo tanto pertenecer al submundo infernal, como el oro, la plata y el resto de los metales, las piedras preciosas y los minerales más valiosos, pero también el fruto de las cosechas de cereales y otras plantas, que "brotan" desde abajo y "surgen" en la superficie procedentes del mundo infernal.

${ }_{17}$ Hillman, J. El sueño y el inframundo, Barcelona/Buenos Aires/México, Paidós, 2004. pp. 48-55.
} 
turaleza ama ocultarse" ${ }^{18} \mathrm{Y}$ esta es justo la forma en la que el estoicismo interpreta el papel cósmico del lógos: como una pauta oculta de la naturaleza que es necesario esforzarse por conocer para poder contemplar el mundo en su justa medida. Han de desvelarse las causas ocultas de las cosas si se quiere aspirar a ser sabio, puesto que, de nuevo con Heráclito, "la cadena invisible es más fuerte que la visible". ${ }^{19}$

El viaje al inframundo emprendido por Creonte en la obra en busca de respuestas representa, así, la necesidad de cada uno de recorrer lo invisible a ciegas para esclarecer lo oculto, puesto que la verdad está en las profundidades, y no en la superficie-apariencia. Pero el hecho de que Creonte franquee los límites bien marcados entre la naturaleza de lo humano y la de lo infrahumano y monstruoso, aunque sea en esa suerte de viaje iniciático de conocimiento, supone una nueva muestra de la indefinición en la que queda el mundo a causa del crimen contra el lógos.

Así, Edipo con sus actos ha provocado que el mundo de la acción humana, que debería mostrarse como claro y ordenado, aparezca como laberíntico. "Es un mal intrincado, una monstruosidad más laberíntica que su célebre Esfinge" ${ }^{20}$ dice de él el fantasma de Layo, interrogado por Creonte, en el momento en que revela los impíos actos que su hijo, en su ignorancia, ha cometido contra el orden natural de las cosas.

Y esa indefinición moral tiene, a su vez, un reflejo cósmico en el mal que asola Tebas. No se trata solo de una peste o plaga natural aunque funesta, sino de una verdadera quiebra del modo pautado de comportarse de la realidad misma.

El agua ha abandonado a los ríos y el color a las hierbas y se ha secado Dirce; con un hilo de agua corre el Ísmeno y con su escaso caudal apenas moja su lecho desnudo. Oscura se desliza por el cielo la hermana de Febo y el firmamento palidece triste con nublados insólitos; ni una estrella brilla en una noche despejada, sino que una niebla pesada y sombría pesa sobre las tierras. Las ciudadelas y elevadas moradas de los dioses del cielo han tomado un aspecto propio del infierno. Niega sus frutos Ceres, aunque la mies está crecida y amarillea temblorosa con sus altas espigas: al secarse los tallos muere estéril el grano. ${ }^{21}$

De esta forma, el mal provocado por el acto contra la naturaleza es el quebrantamiento del orden de la naturaleza mismo.

En efecto, en el estoicismo se concibe como único mal del mundo la maldad humana, identificable con el vicio y la ignorancia, y que consiste de manera expresa y exclusiva en el acto moral contrario a la ley universal de la racionalidad.

\footnotetext{
${ }^{8}$ DK 123.

19 DK 54.

${ }^{20}$ Edipo, 641-2.

${ }^{21}$ Edipo, 42-52.
} 
Es decir, el mal mismo es la transgresión de la norma que dicta el lógos. Pero su efecto no es la ruptura efectiva de la pauta de la naturaleza, sino la angustia y la intranquilidad patética del malvado ante su destino, ante el cosmos y ante sí mismo. "Todo me causa pavor y no me fío de mí mismo", 22 dice Edipo. Y ese temor y desconfianza se transmite a su perspectiva respecto del mundo que le rodea. Y se transmite en concreto en la forma de una intranquilizadora pérdida de referencias en la que ya no puede esperarse de la naturaleza un comportamiento pautado y regular que haga comprensible para la razón humana el devenir en el que se nos da la realidad.

La misma pérdida de referencias ante el crimen contra el lógos, expresada también respecto de la pauta natural, puede encontrarse en otra de las tragedias de Séneca: Medea.

Allí, en el momento en el que la antiheroína trágica termina de concebir su venganza contra Jasón, Medea expresa su extrañeza ante el hecho de que el orden natural no quede trastocado por su crimen:

¿Contempla esto el sol, padre de mi estirpe, y se le sigue contemplando y, sentado en su carro, sigue haciendo el recorrido de siempre por un cielo sereno? ¿No vuelve a su lugar de nacimiento y recorre hacia atrás el camino de ida? ${ }^{23}$

La perturbación de las leyes naturales vuelve, de este modo, a vincularse con el crimen contra el lógos. En este caso el acto que quiebra el orden del mundo, aún solo planeado, es el acto violento de la madre contra los hijos, que contraviene el dictado universal de amar a la propia progenie. Su sola presencia como proyecto en la mente de Medea ya basta en el texto senequiano para presuponer la necesidad de que el mundo deje de ser contemplado como lo que día tras día es igual, expresado por la más evidente de todas las regularidades cotidianas: que el sol sale por el este y se pone por el oeste.

La desorientación de Medea, por lo tanto, es equivalente directa de la de Edipo y la de Tebas entera por el crimen contra la norma a un tiempo sagrada y profana. $\mathrm{Y}$ ambas nos recuerdan en su vehemencia y viveza a aquella otra desorientación consecuencia del crimen contra la divinidad expuesta por Nietzsche en el aforismo 125 de La gaya ciencia:

¿Qué a dónde ha ido Dios? -exclamó-, yo os lo voy a decir. Nosotros lo hemos matado: ¡vosotros y yo! Todos nosotros somos su asesino. Pero ¿cómo hemos podido hacer-

\footnotetext{
${ }^{22}$ Edipo, 26-7.

23 Séneca, Medea, 29-33.
} 
lo? ¿Cómo fuimos capaces de bebernos el mar? ¿Quién nos dio la esponja para borrar el horizonte? ¿Qué hicimos cuando desencadenamos esta tierra de su sol? ¿Hacia dónde se mueve ahora? ¿Hacia dónde nos movemos nosotros? ¿Lejos de todos los soles? ¿No caemos continuamente? ¿Hacia atrás, hacia los lados, hacia delante, hacia todas partes? ¿Acaso hay todavía un arriba y un abajo? ¿No erramos como a través de una nada interminable? ¿No nos roza el soplo del espacio vacío? ¿No se ha vuelto todo más frío? ¿No viene de continuo la noche y más noche? ¿No tendrán que encenderse faroles a mediodía? ${ }^{24}$

Del mismo modo que en Nietzsche, en Séneca se trata también de un crimen contra el fundamento de la realidad. Matar al padre, engendrar hijos con la madre o matar a los propios hijos no son solo crímenes contra sus víctimas, sino que atentan contra el fundamento divino y racional que el estoico considera que todo lo abarca y todo lo gobierna. Por ello supone una desestabilización plena del orden establecido que corre el riesgo de sumir al ser humano en la perplejidad y provocar que se extravíe. Un crimen así supone "borrar el horizonte" porque difumina las marcas fronterizas entre el arriba y el abajo, entre la superficie y el inframundo, como si un rito funesto abriese la tierra y permitiese el paso entre la superficie y el abismo. ${ }^{25}$ Así, el sol ya no debería seguir su pauta eterna, sino abandonarla, como Medea espera, desencadenado de la tierra para seguir un camino azaroso.

Sin la escucha de los dictados del lógos, en opinión del estoicismo, solo nos queda un mundo cambiante caótico e imprevisible en el que toda acción es igualmente injustificada. Y un mundo así no es en la práctica mucho más que una noche eterna de ignorancia, una nada infinita de perpetua indefinición carente de sentido.

En la tragedia, el orden debe ser restaurado con un sacrificio. El lector debe contemplar el acto de purificación que revierta la situación cósmica a su equilibrio original. Por ello, Edipo se arranca los ojos. Por no haber visto los signos que tenía ante sí que le habrían debido llevar a obrar racionalmente, ahora debe extirpar de sí los órganos de su ceguera. Este acto de expiación de arrancarse los ojos no se centra en el dolor, sino que antes que nada separa al culpable de los vivos, pero no lo conduce

\footnotetext{
$\overline{24}$ „Wohin ist Gott?" rief er, "ich will es euch sagen! Wir haben ihn getötet - ihr und ich! Wir alle sind seine Mörder! Aber wie haben wir dies gemacht? Wie vermochten wir das Meer auszutrinken? Wer gab uns den Schwamm, um den ganzen Horizont wegzuwischen? Was taten wir, als wir diese Erde von ihrer Sonne losketteten? Wohin bewegt sie sich nun? Wohin bewegen wir uns? Fort von allen Sonnen? Stürzen wir nicht fortwährend? Und rückwärts, seitwärts, vorwärts, nach allen Seiten? Gibt es noch ein Oben und ein Unten? Irren wir nicht wie durch ein unendliches Nichts? Haucht uns nicht der leere Raum an? Ist es nicht kälter geworden? Kommt nicht immerfort die Nacht und mehr Nacht? Müssen nicht Laternen am Vormittage angezündet werden? (Nietzsche, F. Die fröhliche Wissenschaft. \$125.) La comparación con el texto de Nietzsche que aquí planteamos, con todo, atañe solo al similar modo en que Nietzsche y Séneca reflejan las consecuencias de la quiebra del orden, y no trata de presuponer mayores vínculos entre ambos pensamientos en lo que respecta a este tipo de cuestiones.

25 Véase Séneca, Edipo, 865 y ss.
} 
entre los muertos (lo que podría conllevar un nuevo crimen como el que intenta paliar), y no quiebra las leyes de la naturaleza. Al contrario, es la naturaleza la que queda encargada de "idear" el suplicio de Edipo en adelante. ${ }^{26} \mathrm{Y}$ su separación de su orden social desvincula a Tebas de la falta cósmica. La ceguera de Edipo conlleva la marginalidad como muerte social y familiar reiterada en el tiempo:

Hay que elegir una muerte prolongada. Hay que buscar el camino por el que puedas andar errante sin mezclarte con los sepultados, quedando, no obstante, marginado de los vivos. Muere, pero sin llegar hasta tu padre... ¿ ¿Vacilas, alma mía. ${ }^{27}$

El resultado de su automutilación es cruento, sangriento y terrible, como el tono general de toda la obra. El objetivo final filosófico-pedagógico así lo exige: ha de servir para ejemplificar el modo en que el ignorante del lógos está condenado a sufrir. Quien no escucha los dictados del principio divino racional del universo, según el estoicismo, no logra cambiar su destino (que se ha de imponer de cualquier modo), sino que el único cambio que introduce en el curso de los acontecimientos es su propia infelicidad. Agitado y sufriente, vagará tanto como le quede de vida por un mundo cuya verdadera naturaleza no puede llegar a ver. Y de su pesarosa vida quedará incluso excluida toda auténtica forma de trato social con la humanidad.

La defensa final de la actitud sabia del hombre virtuoso-racional la expresa, hacia el final de la tragedia, la voz del coro:

Los hados nos arrastran; ceded ante los hados; no sirve el inquietarse con preocupaciones para cambiar los hilos del inmutable huso. Todo lo que sufrimos la raza mortal, y todo lo que hacemos viene de lo alto; y Láquesis mantiene las leyes de su rueca, haciéndola girar con mano inexorable. Todo va por la senda que se le ha trazado Y el día primero ya señala el último: no puede un dios cambiar el curso de unas cosas que van encadenadas a sus causas. Hay para cada cosa un orden fijo que no puede cambiar plegaria alguna: a muchos les perjudica el propio miedo; muchos se encuentran con sus hados por temerlos. ${ }^{28}$

\footnotetext{
${ }^{26}$ Edipo, 944-7.

27 Edipo, 950-3.

${ }^{28}$ Edipo, 980-994.
} 
El lógos es en sí el único principio necesario rector del universo. No hay otra divinidad a la que pueda implorarse de modo ajeno a la racionalidad pura de este principio. La plegaria es inútil. La concatenación de cada causa con su efecto es inexorable. El orden del mundo es fijo y ningún acto humano puede, en verdad, llegar a trastocarlo.

El coro, que siempre en la tragedia expone una cierta voz de lo social, se convierte aquí en voz de la humanidad en su conjunto, voz de la razón humana que contempla el orden de la razón universal y desea contribuir a su realización. Y por ello difunde el mensaje último estoico que reside en este texto: el temor al destino es inútil; de nada sirve inquietarse; el único camino racional es la apatía. "Ceded ante los hados". 


\section{Referencias Bibliográficas}

Arnim, H. von. Stoicorum veterum fragmenta. 4 vols, Stuttgart, Teubner , 1923.

Cappelletti, A. J. Los estoicos antiguos, Madrid, Gredos, 1996.

Dixon, V. "Los efectos de inmersión en el teatro de Antonio Buero Vallejo: una puesta al día". Anthropos: Boletín de información y documentación, 79 (1987), 31-36.

Doménech, R. El teatro de Buero Vallejo: una meditación española, Madrid, Gredos, 1979.

Egermann, F. "Seneca als Dichterphilosoph". Neue Jahrbuch für Antike und deutsche Bildung, 3 (1940), 18-36.

Griffin, M. T. Séneca, a Philosopher in Politics, Oxford, Clarendon, 1976.

Henry, D. and Walker, B. "The Oedipus of Seneca: An Imperial Tragedy." In: Boyle, A.J. (Ed.). Seneca Tragicus: Ramus Essays on Senecan Drama. Berwick, 1983.

Hillman, J. El sueño y el inframundo, Barcelona/Buenos Aires/México, Paidós, 2004.

Lefèvre, E. "Quid ratio possit? Senecas Phaedra als stoisches Drama." WS (N.F.) 3: 131-160, 1969.

Marías, J. "Introducción a la filosofía estoica", en Séneca, Sobre la felicidad, Madrid, Alianza, 1984. pp. 9-38.

Marti, B. M. "The prototypes of Seneca's tragedies", Classical Philology 42 (1947), 1-16.

Nietzsche, F. Die fröhliche Wissenschaft, Chemnitz, Verlag von Ernst Schmeitzner, 1882.

Rist, J. M. La filosofía estoica. Crítica, Barcelona, 1995.

Rosenmeyer, T.G. 1989. Senecan Drama and Stoic Cosmology. Berkeley/Los Angeles/London, 1989.

Sellars, J. Stoicism, Berkeley/Los Angeles, University of California Press, 2006.

Séneca, L. A. Tragedias. 2 vols. Traducción de Jesús Luque Moreno, Madrid, Gredos, 1979-1980. 
Sklenár, R. J. “Seneca, Oedipus 980-993: How Stoic a Chorus?”, Classical Journal, Vol. 103, no 2 (2007-8), 183-194.

Töchterle, K. Lucius Annaeus Seneca: Oedipus. Kommentar mit Einleitung, Text und Übersetzung. Heidelberg, 1994.

Veyne, P. Séneca y el estoicismo, México, Fondo de Cultura Económica, 1995.

Wilson, E. Séneca. Rialp, Madrid, 2016.

DOI: http://doi.org/10.15366/bp2019.22.020

Bajo Palabra. II Época. No 22. Pgs: 375-390 
